$\because$ P FIVED

1.. 3n 395

USTI

\section{CONFINEMENT AND STABILITY}

OF DIII-D NEGATIVE

CENTRAL SHEAR DISCHARGES

by

L.L. LAO, T.S. CASPER, V.S. CHAN, M.S. CHU, C.B. FOREST,

R.J. GROEBNER, F.L. HINTON, Y. KAWANO, E.A. LAZARUS,

Y.R. LIN-LIU, M.E. MAUEL, W.H. MEYER, R.L. MILLER,

G.A. NAVRATIL, T.H. OSBORNE, C.L. RETTIG, G. REWOLDT

E.J. STRAIT, T.S. TAYLOR, W.M. TANG, A.D. TURNBULL,

R.E. WALTZ, and THE DIII-D TEAM

DECEMBER 1995 


\section{DISCLAIMER}

This report was prepared as an account of work sponsored by an agency of the United States Government. Neither the United States Government nor any agency thereof, nor any of their employees, makes any warranty, express or implied, or assumes any legal liability or responsibility for the accuracy, completeness, or usefulness of any information, apparatus, product, or process disclosed, or represents that its use would not infringe privately owned rights. Reference herein to any specific commercial product, process, or service by trade name, trademark, manufacturer, or otherwise, does not necessarily constitute or imply its endorsement, recommendation, or favoring by the United States Government or any agency thereof. The views and opinions of authors expressed herein do not necessarily state or reflect those of the United States Government or any agency thereof. 


\section{CONFINEMENT AND STABILITY OF DIII-D NEGATIVE CENTRAL SHEAR DISCHARGES}

by

L.L. LAO, T.S. CASPER, V.S. CHAN, M.S. CHU, C.B. FOREST, R.J. GROEBNER, F. L. HINTON, Y. KAWANO, † E.A. LAZARUS,

Y.R. LIN-LIU, M.E. MAUEL, W.H. MEYER, R.L. MILLER, G.A. NAVRATIL, T.H. OSBORNE, C.L. RETTIG, ${ }^{\natural}$ G. REWOLDT,

E.J. STRAIT, T.S. TAYLOR, W.M. TANG, ${ }^{b}$ A.D. TURNBULL,

R.E. WALTZ, and THE DIII-D TEAM

This is a preprint of a paper presented at the Fifth Workshop on H-Mode Physics, September 18-20, 1995, Princeton, New Jersey, and to be printed in the Proceedings.

Work supported by U.S. Department of Energy Contract

Nos. DE-AC03-89ER51114, W-7405-ENG-48, DE-AC05-84OR21400, and DE-AC02-76CH03073, and Grant Nos. DE-FG03-95ER54309, DE-FG02-89ER53297, and DE-FG03-86ER53266

*Lawrence Livermore National Laboratory

$\dagger$ Japan Atomic Energy Research Institute

$\ddagger$ Oak Ridge National Laboratory

"Columbia University

University of California, Los Angeles

${ }^{b}$ Princeton Plasma Physics Laboratory

GENERAL ATOMICS PROJECT 3466 DECEMBER 1995

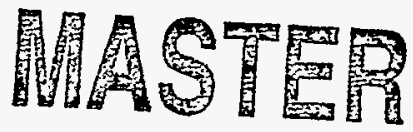




\title{
Confinement and stability of DIII-D negative central shear discharges
}

\author{
L L Lao $\dagger$, K H Burrell $\uparrow$, T S Casper $\ddagger$, V S Chan $\dagger$, M S Chu $\dagger$, \\ C B Forest $\dagger, \mathbf{R} \mathbf{J}$ Groebner $\dagger$, F L Hinton $\dagger$, Y Kawano *, \\ E A Lazarus $\diamond$, Y R Lin-Liu $\uparrow$, M E Mauel §, W H Meyer $\ddagger$, \\ R L Miller $\uparrow$, G A Navratil §, T H Osborne $\uparrow$, C L Rettig I, \\ G Rewoldt $\not$, B W Rice $\ddagger$ B W Stallard $\ddagger$, E J Strait $\uparrow$, T S Taylor $\dagger$, \\ W M Tang a, A D Turnbull $\dagger$, R E Waltz $\dagger$, and the DIII-D Team \\ $\dagger$ General Atomics, PO Box 85608, San Diego, California, USA \\ $\ddagger$ Lawrence Livermore National Laboratory, Livermore, California, USA \\ * Japan Atomic Energy Research Institute, Naka-machi, Naka-gun, \\ Ibaraki-ken, Japan \\ $\checkmark$ Oak Ridge National Laboratory, Oak Ridge, Tennessee, USA \\ $\S$ Columbia University, New York City, New York, USA \\ II University of California, Los Angeles, California, USA \\ a Princeton Plasma Physics Laboratory, Princeton, New Jersey, USA
}

\begin{abstract}
Negative central magnetic shear (NCS) discharges with $\beta_{\mathrm{N}}$ $\leq 4, \mathrm{H} \leq 3$, and up to $80 \%$ of the current non-inductively driven are reproducibly produced in the DIII-D tokamak. Strong peaking of $T_{i}$, plasma rotation, and in some cases $n_{e}$ are observed inside the NCS region. Transport analysis shows that the core ion thermal diffusivity is substantially reduced and near the neoclassical value after the formation of the internal transport barrier. The negative central shear is necessary but not sufficient for the formation of this transport barrier. The power required for the formation appears to increase with the toroidal magnetic field. The high performance phase of $\mathrm{H}$-mode NCS discharges often ends with an ELM-like collapse initiated from the edge whereas the L-mode discharges which have a more peaked pressure profile tend to end with a more global $n=1 \mathrm{MHD}$ event.
\end{abstract}

Keywords. Tokamak; DIII-D; negative central shear; confinement; stability

\section{Introduction}

Plasma configurations with negative central magnetic shear (NCS) have been proposed $[1,2]$ as one of the leading scenarios for steady state advanced tokamak operation because of their potential to provide good confinement, improved stability, and large fraction of well aligned bootstrap current. These ingredients are among the key elements for a compact and economically attractive future fusion power plant. In this paper, the confinement and stability results from the recent DIII-D NCS experiments [3] are summarized and discussed. 
In these experiments, $\mathrm{H}$ - and $\mathrm{VH}$-mode discharges with negative or nearly negative magnetic shear profiles, and confinement enhancement factor $\tau_{E} / \tau_{\text {ITER-89P }} \equiv \mathrm{H}>3$, normalized beta $\beta_{\mathrm{T}} /\left[\mathrm{I} /\left(\mathrm{aB}_{\mathrm{T}}\right)\right] \equiv \beta_{\mathrm{N}}>4$, have been produced either separately or simultaneously. NCS discharges with an L-mode edge and $\mathrm{H}>2$ due to reduced core transport have also been obtained [4]. These discharges have strongly shaped double-null divertor poloidal cross sections with elongations of $\kappa \sim 2$. They are characterized by peaked pressure profiles with $\mathrm{P}(0) /\langle\mathrm{P}\rangle \sim 3$ to 5 and large fraction, $50 \%$ to $80 \%$, of the current noninductively driven.

The production of NCS discharges is described in Section 2. The formation of an internal transport barrier within the NCS region is discussed in Section 3. The MHD stability properties of these discharges are summarized in Section 4 together with a brief discussion of the discharge optimization to improve the plasma performance.

\section{Production of NCS discharges}

In these experiments, NCS discharges are reproducibly obtained by injecting codirectional neutral beams early in the current ramp of a low density target plasma. Using this technique, NCS discharges with $2 \leq q_{0} \leq 15,1 \leq q_{\min } \leq 3$, and $0.55 \leq l_{i} \leq 1.1$ have been produced in L-mode, $\mathrm{H}$-mode, and ELMing $\mathrm{H}$-mode plasmas [5]. The primary factors affecting the formation of the $q$ profile and its evolution are the target density, the beam power, the relative timing between the current ramp and the beam injection phases, and the transition time from $\mathrm{L}-$ to $\mathrm{H}$-mode.

The temporal evolution of a NCS discharge is given in figure 1. Starting from a low target density $\mathrm{n}_{\mathrm{e}} \sim 1 \times 10^{19} \mathrm{~m}^{-3}$ discharge, $4.6 \mathrm{MW}$ of neutral beam power is injected into the plasma during early current ramp up phase starting from $300 \mathrm{~ms}$. This delays the penetration of the ohmic current into the plasma core and results in a NCS plasma with axial $\mathrm{q}_{0}>\mathrm{q}_{\min }$ as shown in figure 1(b). Off-axis beam and bootstrap current reinforces the hollow current density profile. The q profile is reconstructed from full equilibrium analysis using internal magnetic field line pitch angle measurements from a 16-channel MSE system. This particular discharge has $\mathrm{B}_{\mathrm{T}}=1.6 \mathrm{~T}$ and $\mathrm{I}=1.2 \mathrm{MA}$. Discharges at higher $\mathrm{B}_{\mathrm{T}}=2.1 \mathrm{~T}$ typically have a higher $\mathrm{q}_{0}$ and a stronger inverted $\mathrm{q}$ profile due to a higher $\mathrm{T}_{\mathrm{e}}$.

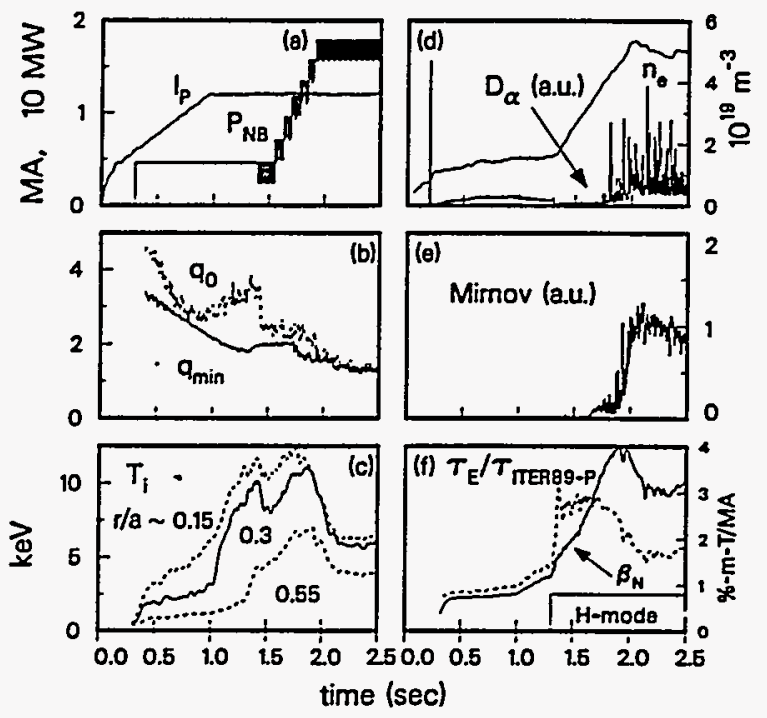

Figure 1. Time evolution of DIII-D NCS discharge 84736

\section{Formation of internal transport barrier}

Strong peaking of $T_{i}$, plasma rotation $\Omega$, and in some cases $n_{e}$ [4], is often observed within the NCS region due to the formation of an internal transport barrier. As illustrated in figure 1(c), shortly after the current flat-tops at $1 \mathrm{sec}, \mathrm{T}_{\mathrm{i}}$ inside the NCS region increases sharply preceded by a rise of q0. An almost simultaneous increase of $\Omega$ is also observed in the same area. The sharpest rise occurs in the region where the negative magnetic shear is strong. The beam power is held constant at 4.6 MW. Throughout this phase $T_{e}$ and $n_{e}$ change only weakly. As shown in figure 1 (f), the formation of the core transport barrier also leads to an increase in the global energy confinement time as measured by $\mathrm{H}$. 


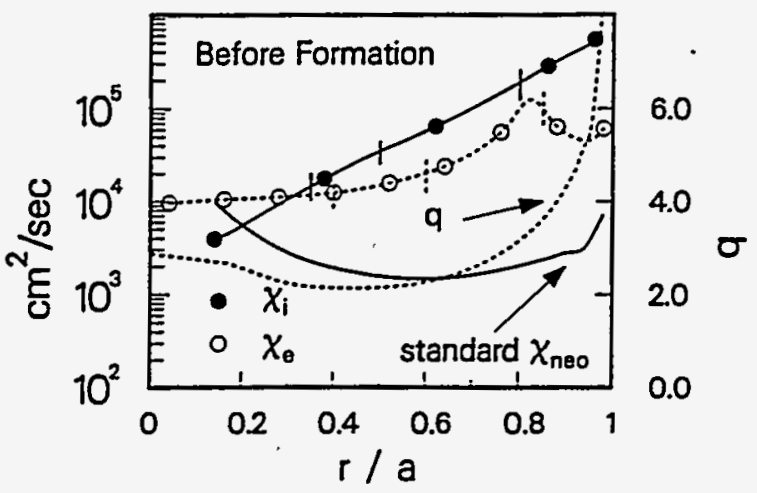

Figure 2. Comparison of ion and electron thermal diffusivities and $q$ profiles before and after the formation of the internal transport barrier for DIII-D NCS discharge 84736 at the $L-$ mode times $t=1.0$ and $1.1 \mathrm{sec}$

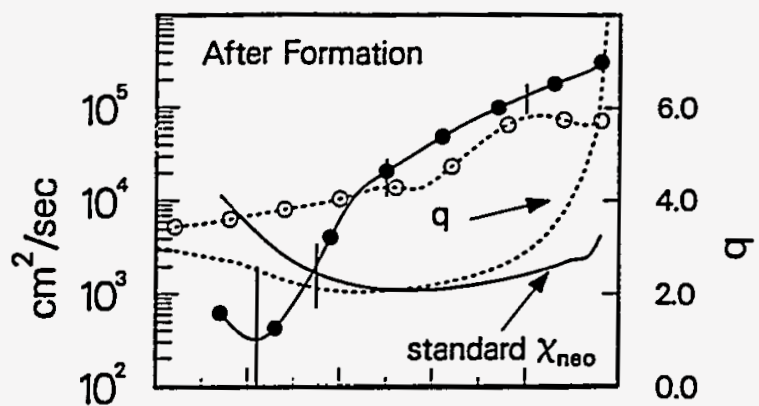

As shown in figure 2, the sharp local rise of $T_{i}$ significantly reduces the ion thermal diffusivity to below the standard neo-classical values in the area $\mathrm{r} / \mathrm{a} \sim 0.25$ where the negative magnetic shear is strong. In this central region, where the ion poloidal gyro-radius becomes comparable with its temperature gradient scale length and the ion banana width is larger than its radial distance to the magnetic axis, the standard neo-classical approximation becomes inaccurate and overestimates the ion thermal diffusivity. Preliminary analysis of neo-classical ion thermal diffusivity which includes this finite banana orbit correction near the magnetic axis suggests that the experimental ion thermal diffusivity is near this corrected neoclassical value.

While $\chi_{i}$ is reduced significantly with the formation of the transport barrier, the changes in particle and elecıron thermal diffusivities are small. Before the formation of the internal transport barrier, thermal conduction is the dominant loss mechanism inside the NCS region for both the ion and the electron channels. After the formation, conduction Joss inside the NCS region remains important only for the electron channel.

In this discharge, formation of the internal transport barrier occurs at a constant beam power of $4.6 \mathrm{MW}$ during the L-mode phase which is preceded by an increase of q0. This core transport barrier formation is independent of the edge transport barrier formed after the discharge transits into the $\mathrm{H}$-mode phase around $1.31 \mathrm{sec}$, as shown in figure 1 . For discharges at higher $\mathrm{B}_{\mathrm{T}}=2.1 \mathrm{~T}$, the formation of the barrier occurs at a higher beam power and is triggered by an increase in beam power. A similar observation of a power threshold requirement for the formation of the internal transport barrier has also been made in TFTR NCS discharges [6]. The results are summarized in figure 3. Also included is a data point from TFTR NCS discharges [6]. The threshold power required for the formation of the transport barrier appears to increase with the toroidal magnetic field. Further experiments are needed to verify this dependence and establish the detailed scaling relationship.

Kinetic stability analysis of the toroidal trapped-particle drift modes using the FULL code [7] suggests that the negative central shear may contribute to the formation of the internal transport barrier to allow the build-up of the very steep $\mathrm{T}_{\mathrm{i}}$ gradient in the NCS region.

\section{MHD Stability of NCS discharges}

The NCS discharges are characterized by peaked pressure profiles with $P(0) /\langle P\rangle \sim 3$ to 5. High $\mathrm{n}$ ideal ballooning analysis suggests that the negative central shear is necessary to allow the build-up of the steep central pressure gradient by improving the access to the second ballooning stable regime.

The observation of low $\mathrm{n}$ saturated modes depends on the details of the proximity of the low magnetic shear region to low order rational $q$ surfaces, the minimum $q$ value, and 
the extent of the rotational shear. In these NCS discharges, MHD activity is usually small or absent when $\mathrm{q}_{\min }>2$. Increased $\mathrm{MHD}$ activity is often observed when $\mathrm{q}_{\min }$ passes through 2 , which may lead to transient degration of core confinement as shown in figure 1 (c) around $\mathrm{t}=1.42 \mathrm{~s}$. However, in a number of discharges, $\mathrm{q}_{\mathrm{min}}$ passes through 2 with little or no MHD activity. Initial results from resistive analysis suggest that a double tearing mode may be stabilized by differential plasma rotation at moderate $\beta_{\mathrm{N}}$.

The NCS discharges produced so far have been limited to $\beta_{N} \leq 4$ and $\mathrm{H} \leq 3$ due to MHD instabilities. The high performance phase of $\mathrm{H}$-mode NCS discharges often terminates due to a fast growing low n MHD event [figure $1(\mathrm{e})$, around $1.9 \mathrm{~s}$ ] initiated from the edge region, as usually observed in VH-mode discharges. This is consistent with the results from ideal stability analysis. The high performance phase of L-mode NCS discharges which have more peaked pressure profiles tend to end with a more global fast growing $n=1$ event. By delaying the beam injection phase to reduce the build-up of current density in the edge region while still allowing a nearly negative magnetic shear profile to develop, $\mathrm{VH}-$ mode discharges with $\beta_{\mathrm{N}}>4$ and $\mathrm{H}>3$ have been obtained.

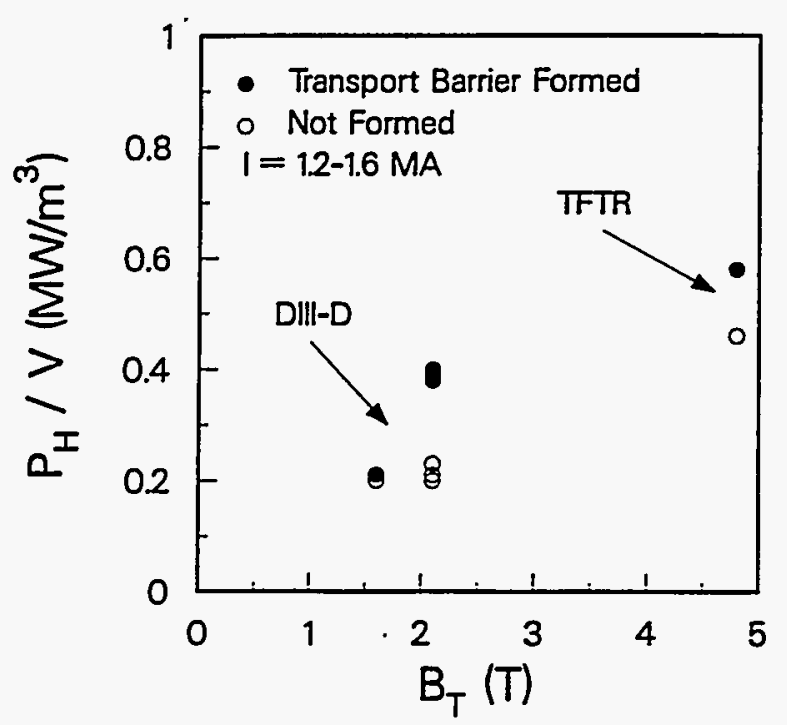

Figure 3. Threshold power for the formation of internal transport barrier in NCS discharges

\section{Acknowledgment}

This is a report of work sponsored by the U.S. Department of Energy under Contract Nos. DE-AC03-89ER51114, W-7405-ENG-48, DE-AC03-84OR21400, and DE-AC02-76CH03073, and Grant Nos. DE-FG03-95ER54309, DEFG02-89ER53297, and DE-FG0386ER53266.

\section{References}

[1] Turnbull A D et al. 1995 Phys. Rev. Lett. 73718

[2] Kessel CE et al. 1994 Phys. Rev. Lett. 721212

[3] Strait E J et al. 1995 to be published in Phys. Rev. Lett.

[4] Rice B W et al. 1995 General Atomics Report GA-A22129 to be submitted to Nuclear Fusion

[5] Rice B W et al. 1995 General Atomics Report GA-A22127 submitted to Plasma Phys. and Contr. Fusion

[6] Levinton M et al. 1995 to be published in Phys. Rev. Lett.

[7] Rewoldt $\mathrm{R}$ et al. 1982 Phys. Fluids 25480 


\section{* general atomics}

P. O. BOX 85608 SAN DIEGO, CA $92186-9784$ (619) 455-3000 